\title{
A Factory Analysis on the Proportion of Defects Reduction in The Animal Feed Pellet Production Process using Design of Experiment Analysis
}

\author{
Kritsana Kraiwitanusorn, Chaiyaporn Vongpisal, and Juthamas Choomlucksana \\ Department of Materials Handling and Logistics Engineering, Faculty of Engineering \\ King Mongkut's University of Technology North Bangkok, \\ 1518, Pracharat Rd., Bangsue, Bangkok, 10800, Thailand.
}

\begin{abstract}
The aim of this research is to reduce a number of defects during a feed pellet production process to improve customer satisfaction. A factory case study produces the feed pellets for several species such as food for pigs, chickens, and ducks. Production data from January to June 2017 manufacturing found that the manufacturing defects rate were about $3.32 \%$. The data showed that the overall defects originated from different problems; 1) cracked or broken food; 2) high humidity; 3) distorted of product color; and 4) an ingredient error, respectively. Statistical methods, design analysis, and cause analysis techniques e.g. the Ishikawa diagram, Pareto chart, and FMEA (Failure Mode and Effects Analysis) were applied to help the factory to identify the main root cause of the defects and the potential failure modes of the factory case study. Due to an increasing number of complaints, this study only concentrated on the duck feed pellet production process. The study was divided into two parts: finding the root cause of the defects, which are the most critical factors for further analysis, and applying an experimental statistical design to decrease the number of defects during the duck pellet production process. The problem with cracked or broken pellets (dust) was found as the main factor affecting the production defects. Results showed that the main factors contributing to the amount of dusk in the duck feed productions came from three factors as follow: the thickness of die, distance between compression rollers and die, and time and temperature of mill machine needed during compressing the duck feed pellet production. Both the fractional factorial experimental design, $2^{\mathrm{k}}$ and $3^{\mathrm{k}}$, were used to evaluate the influence of each factor on the duck feed production defects. The results by using the factorial $2^{\mathrm{K}}$ experimental show that the most important variable in duck pellets production were thickness of the die, distance between compression rollers and die, and temperature of mill machine needed during compressing the duck feed pellet production while time was not an interaction effect in this problem. The $3^{\mathrm{k}}$ factorial design was used to determine the interaction effects for the duck pellets production process. The experiment was ran and tested for 3 months. The final outcomes showed a significant reduction of defects from $2.51 \%$ to $1.09 \%(\mathrm{P}<0.01)$. The results indicated that thickness $-20 \mathrm{~mm}$. of the die, $0.05 \mathrm{~mm}$ of distance between compression rollers and die, and 95 degree Celsius of temperature of mill machine needed during compressing the duck feed pellet production would be the most appropriate set of pelleting machine for the duck production process case study
\end{abstract}

Key words: Pelleting process, Design of Experiment, Factorial design, Failure mode effect analysis

\section{INTRODUCTION}

The level of industrial production of the country has grown quickly due to an increase competitive in price and quality of goods. It is necessary for companies to compete with other manufacturers by ensuring and achieving customer satisfaction. As, a reliable product quality and customer satisfaction are the main factors that contribute to industry success. Thus entrepreneurs are needed to produce all goods with fewer resources that meet the standards and requirements of customers. The factory used for this case study is a leader of Thailand's agro-industrial and food, producing about 48,000 tons of goods per month). The main products

Corresponding Author: Juthamas Choomlucksana, Dept. of Materials Handling and Logistics Engineering, 1518, Pracharat 1 Rd., Wongsawang, Bangsue, Bangkok, 10800, Thailand, Cell phone: +66-2-555-2000 ext.8631 
are animal feed product including pig feed, chicken feed, and duck feed in both tablets and powder forms. Since January until June 2017, the factory received an increasing number of customer's complaints about the product quality. The production data showed that there were about $478,359 \mathrm{~kg}$, or about of $3.32 \%$ of products that fails to meet factory standard. Therefore, the production processes are affected by various deviations over time which resulting in producing the products that differ from the initial manufacturing setting.

This research study has two objectives. The first objective is to identify factors that influencing product quality during the feed production process. The second is to conduct a statistical study to assess the impact of those factors in order to decrease the number of product defects and to improve customer satisfaction. Several cause analysis techniques such as the Ishikawa diagram, Pareto chart, and FMEA, were applied to identify potential factors causing an overall the product defects in the feed pellet production process. The Ishikawa diagrams, also called cause-and-effect diagrams, developed by Kaoru Ishikawa in 1968 which illustrates the link between possible cause and effect. The problem is usually shown as a fish's head, and causes are typically showed as a skeleton of the fish. This tool is commonly used for problem solving during the analyze phase like PDCA and DMAIC. Furthermore, the FMEA is also widely used for the quality improvement and risk assessment techniques in almost all business industries such as in manufacturing and service centers. The FMEA uses a Risk Priority Number (RPN) methodology, which consists of "S", "O", and "R" to analyze the risks associated with each identification failure. The severity (S) means the consequence of the failure should it occur. The occurrence $(\mathrm{O})$ means the probability or frequency of the failure occurring, and the detection (D) means the probability of failure being detected before the impact in realized [1]. Each "S", "O", and "D" is identified on a numerical scale of 1 to 10 . The FMEA has been successfully applied to identify failure of quality and safety in many areas of business. For example, Laura et al. [2] used the FMEA to improve a health care process and quality. Group members met weekly to define FMEAs with a goal of reducing risk in the patient safety toolkit. Moreover, Ioannis et al. [3] applied the FMEA for risk assessment at each step of the potato chips production. RPN values from the FMEA were determined to optimize prevention and avoidance of hazards occurring in the manufacturing process. So far, techniques, the Ishikawa diagram and
Failure Mode and Effect Analysis techniques are likely to be applied in additional studies [2-4].

\section{EXPERIMENT}

\section{Case Description}

The subject of this case study is a leading agro-industrial factory that manufactures many kinds of animals feed products e.g., food for pigs, chickens, and ducks in powder and tablet forms. The feed production process consists of four main processes, grinding, weighing, mixing, and pelleting as shown in figure 1 .

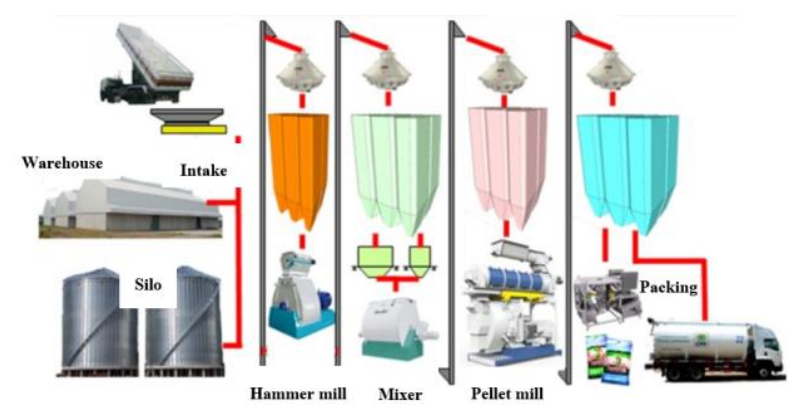

Fig 1 the Main Steps in Feed pellet Production Process

The factory found that there were an increasing number of customer complaints during January to June, 2017 regarding the duck feed pellets. The data showed that the products did not meet standards of quality, which can be influenced by several factors. About $3.32 \%$ of the product defects came from cracked or broken feed pellets (dust), high humidity, distorted of product color, as error of product ingredients, the product defective, as shown in figure 2.

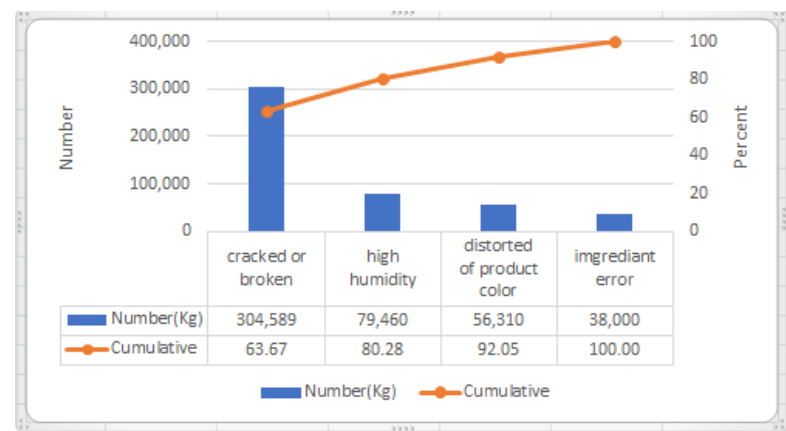

Fig 2 the Proportion of Duck Product Problems using Pareto Charts

The data from figure 2 showed that dust and high humidity account for $80 \%$ of the customer complaints.

Table 1 shows the comparative between a standard indicator and data received from Jan to July 2017. 
Juthamas Choomlucksana, / Journal of Engineering and Science Research, 2 (2), 2018, Pages: 26-33

Table 1. An Information of the Standard Indicators of Each Parameter Compared with the Data Received from the Production.

\begin{tabular}{|l|c|c|}
\hline \multicolumn{1}{|c|}{ Indicator } & Standard Data & Data during January to July 2017 \\
\hline 1.Pellet durability index (PDI) & $96 \%-99 \%$ & $96 \%-97 \%$ \\
\hline 2. Physical (Color and external appearance) & Color Consistency & Not Consistency \\
\hline 3. Fine percentage & $<5.0 \%$ & $7.2 \%$ \\
\hline 4. Moisture & $<12.0 \%$ & $15.3 \%$ \\
\hline
\end{tabular}

\section{Cause analysis}

The Ishikawa diagram and FMEA were used to find all the possible main cause that could effect on the product defects. The causes of customer complaints coming from dust or broken products were identified by using the Ishikawa diagram as shown in figure 3. Results found that man, machines, methods, and material are the main problem. However, in this study only man, machine, and method were considered as a first priority for defects reduction and improvement. Next, Factors including man, machine, and methods were analyzed using the FMEA technique. The FMEA process was used to focus on an identifying all of the possible failure that found in the Ishikawa analysis. The RPN was determined by multiplying the ranking for these three factors with $(\mathrm{S} x$ $\mathrm{O} \times \mathrm{D})$.
An engineering team at the factory is the one who ranking number of "S", "O", and "D".

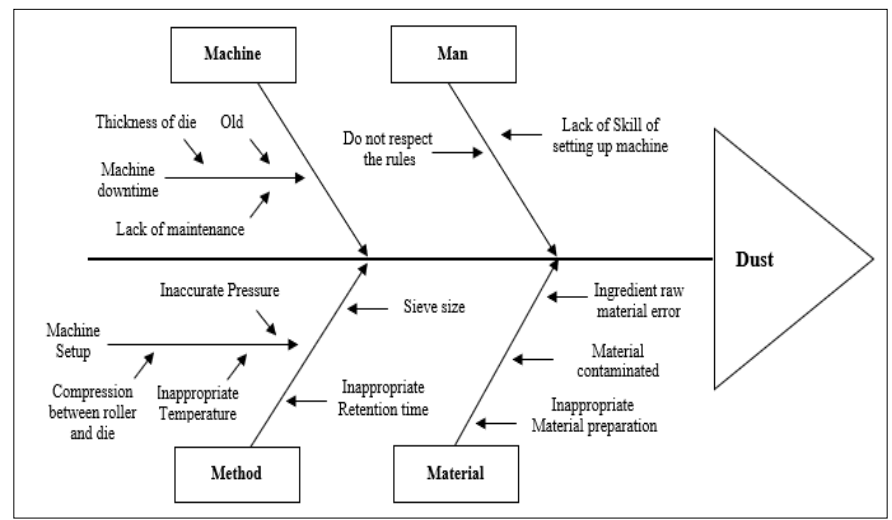

Fig 3 Ishikawa Diagram of Dust Problem

Table 2 FMEA in Feed Pallet Compression Process, a Factory Case Study.

\begin{tabular}{|c|c|c|c|c|c|c|c|c|}
\hline Process & $\begin{array}{l}\text { Potential } \\
\text { Failure } \\
\text { Mode }\end{array}$ & $\begin{array}{l}\text { Potential Effect } \\
\text { (S) of Failure }\end{array}$ & $\mathbf{S}$ & $\begin{array}{c}\text { Potential Cause (s) of } \\
\text { Failure }\end{array}$ & $\mathbf{O}$ & $\begin{array}{l}\text { Current Controls, } \\
\text { Prevention }\end{array}$ & D & $\begin{array}{l}\mathbf{R} \\
\mathbf{P} \\
\mathbf{N}\end{array}$ \\
\hline \multirow[t]{6}{*}{$\begin{array}{c}\text { Pallet } \\
\text { Compression }\end{array}$} & Dust & \multirow{6}{*}{$\begin{array}{c}\text { Inefficient Pellet } \\
\text { Weight } \\
\text { (Reprocess) }\end{array}$} & 9 & $\begin{array}{l}\text { Material : Raw Material } \\
\text { Ingredient }\end{array}$ & 10 & $\begin{array}{l}\text { Check customer } \\
\text { requirement/ } \\
\text { production standard }\end{array}$ & 1 & 90 \\
\hline & & & 9 & $\begin{array}{l}\text { Machine : Thickness of } \\
\text { die }\end{array}$ & 9 & $\begin{array}{l}\text { Process standard/ } \\
\text { Observation of the } \\
\text { machine }\end{array}$ & 1 & 81 \\
\hline & & & 9 & $\begin{array}{l}\text { Machine }: \text { Distance } \\
\text { between compression } \\
\text { rollers and die }\end{array}$ & 7 & $\begin{array}{l}\text { Process standard/ } \\
\text { Observation of the } \\
\text { machine }\end{array}$ & 4 & $\underline{252}$ \\
\hline & & & 9 & $\begin{array}{l}\text { Method: Temperature of } \\
\text { mill machine needed } \\
\text { during compressing the } \\
\text { duck feed pellet } \\
\text { production }\end{array}$ & 6 & $\begin{array}{l}\text { Process standard/ } \\
\text { Observation of the } \\
\text { machine }\end{array}$ & 4 & $\underline{216}$ \\
\hline & & & 9 & $\begin{array}{l}\text { Method: Retention time } \\
\text { needed to mix } \\
\text { ingredients }\end{array}$ & 6 & $\begin{array}{l}\text { Process standard/ } \\
\text { Observation of the } \\
\text { machine }\end{array}$ & 2 & $\underline{108}$ \\
\hline & & & 9 & Man: Operators & 1 & $\begin{array}{l}\text { Observation of the } \\
\text { operator work }\end{array}$ & 5 & 45 \\
\hline
\end{tabular}




\section{Experimental Design}

Three variables including (1) the distance between compression rollers and die, (2) the temperature of mill machine needed during compressing the duck feed pellet production, and (3) the retention time needed to mix ingredients were shown as the potential cause of failure with the highest RPN values $(252,216$, and 108, respectively). Moreover, all possible variables such as the thickness of the die that influencing the feed pellet quality that found by using the FMES were analyzed. Therefore, only the ingredient raw materials formulation will not include in this study because all raw material formula came from the customer requirements.

Each variable is detailed as follows:

- Distance between the compression rollers and the die: Study found that the distance between the compression rollers and the die are required to adjust often. If the roller is too far from the die, the feed pellet will too hard which may affect the roller erosion. On the other hand, if the roller is too close to the die, the die may break and the pellet machine will simple be blocked.
- Temperature of mill machine needed during compressing the duck feed pellet production: If the temperature is too high, the feed pellet will have an unusual color. On the other hand, if the roller is too close to the die, the die may break, and the pellet machine will simply be blocked.

- Retention time takes to mix ingredients: If the retention for mixing the feed pellet is too short, the feed pellet will not stick together.

- Thickness of the die during pallet compression: The thickness of the die depends on the size of the die hole. If the die is too thick, the capacity of the machine will reduce slightly and the die will erode easily.

Next the $2^{\mathrm{k}}$ factorial design and $3^{\mathrm{k}}$ factorial design were used to indicate the parameters that most influenced on the product quality. In the hypothetical example, the $2^{4}$ factorial designs were used to determine how the mixing process parameters influence on the product quality during the screening process. The $2^{4}$ would be equivalently, $2 \times 2 \times 2 \times 2$ with involved sixteenth experimental. Table 3 shows an inferior level and superior level of each factor.

Table 3. Factors and Levels of the $2^{4}$ Factorial Design.

\begin{tabular}{|l|c|c|}
\hline \multicolumn{1}{|c|}{ Factors } & Inferior level $(-)$ & Superior level $(+)$ \\
\hline (A) Distance between compression rollers and die & $0.05 \mathrm{~mm}$. & $0.15 \mathrm{~mm}$. \\
\hline $\begin{array}{l}\text { (B) Temperature of mill machine needed during } \\
\text { compressing the duck feed pellet production }\end{array}$ & 85 Celsius & 95 Celsius \\
\hline (C) Retention time needed to mix ingredients & 15 second & 25 second \\
\hline (D) Thickness of die & $-10 \mathrm{~mm}$. & $-20 \mathrm{~mm}$. \\
\hline
\end{tabular}

The $2^{4}$ factorial designs were determined using only two levels for each factor by using Minitab version 16 software. If all factory levels are evaluated, the factory cost will increase onto the stop line; this can also affect other processes.
Two parameters interactions for each pair were considered. Table 4 shows the results of the experimental factorial design with $2^{4}$ in three repeated experiments (the efficiency difference is statistically significant at the 0.01 level).

Table 4. Results of Experiments Factorial $2^{4}$ with Three Repeated Experiments.

\begin{tabular}{|c|c|c|c|c|c|c|c|}
\hline & \multicolumn{3}{|c|}{ Factor } & \multicolumn{3}{c|}{$\begin{array}{c}\text { Defects Proportion } \\
\text { (Replicate) }\end{array}$} \\
\cline { 2 - 8 } No. & $\begin{array}{c}\text { Thickness } \\
\text { of die } \\
\text { (mm.) }\end{array}$ & $\begin{array}{c}\text { Temperature of } \\
\text { mill machine } \\
\text { needed during } \\
\text { compressing the } \\
\text { duck feed pellet } \\
\text { production } \\
\text { (Celsius) }\end{array}$ & $\begin{array}{c}\text { Distance between } \\
\text { compression rollers } \\
\text { and die } \\
\text { (mm.) }\end{array}$ & $\begin{array}{c}\text { Retention time } \\
\text { needed to mix } \\
\text { ingredients } \\
\text { (Second) }\end{array}$ & $\begin{array}{c}\mathbf{1} \\
\text { (Kg.) }\end{array}$ & $\begin{array}{c}\mathbf{2} \\
\text { (Kg.) }\end{array}$ & $\begin{array}{c}\text { 3 } \\
\text { (Kg.) }\end{array}$ \\
\hline 1 & -10 & 85 & 0.05 & 15 & 0.83 & 0.86 & 0.87 \\
\hline
\end{tabular}


Juthamas Choomlucksana, / Journal of Engineering and Science Research, 2 (2), 2018, Pages: 26-33

\begin{tabular}{|c|c|c|c|c|c|c|c|}
\hline \multirow[b]{2}{*}{ No. } & \multicolumn{4}{|c|}{ Factor } & \multicolumn{3}{|c|}{$\begin{array}{l}\text { Defects Proportion } \\
\text { (Replicate) }\end{array}$} \\
\hline & $\begin{array}{c}\text { Thickness } \\
\text { of die } \\
\text { (mm.) }\end{array}$ & $\begin{array}{l}\text { Temperature of } \\
\text { mill machine } \\
\text { needed during } \\
\text { compressing the } \\
\text { duck feed pellet } \\
\text { production } \\
\text { (Celsius) }\end{array}$ & $\begin{array}{l}\text { Distance between } \\
\text { compression rollers } \\
\text { and die } \\
(\mathrm{mm} .)\end{array}$ & $\begin{array}{l}\text { Retention time } \\
\text { needed to mix } \\
\text { ingredients } \\
\text { (Second) }\end{array}$ & $\begin{array}{c}1 \\
(\mathrm{Kg} .)\end{array}$ & $\begin{array}{c}2 \\
(\mathrm{Kg} .)\end{array}$ & $\begin{array}{c}3 \\
(\mathrm{Kg} .)\end{array}$ \\
\hline 2 & -20 & 85 & 0.05 & 15 & 0.54 & 0.58 & 0.5 \\
\hline 3 & -10 & 95 & 0.05 & 15 & 0.72 & 0.69 & 0.71 \\
\hline 4 & -20 & 95 & 0.05 & 15 & 0.32 & 0.29 & 0.33 \\
\hline 5 & -10 & 85 & 0.15 & 15 & 0.82 & 0.89 & 0.9 \\
\hline 6 & -20 & 85 & 0.15 & 15 & 0.4 & 0.46 & 0.5 \\
\hline 7 & -10 & 95 & 0.15 & 15 & 0.57 & 0.61 & 0.56 \\
\hline 8 & -20 & 95 & 0.15 & 15 & 0.29 & 0.35 & 0.33 \\
\hline 9 & -10 & 85 & 0.05 & 25 & 0.9 & 0.85 & 0.82 \\
\hline 10 & -20 & 85 & 0.05 & 25 & 0.58 & 0.56 & 0.52 \\
\hline 11 & -10 & 95 & 0.05 & 25 & 0.7 & 0.72 & 0.69 \\
\hline 12 & -20 & 95 & 0.05 & 25 & 0.3 & 0.28 & 0.33 \\
\hline 13 & -10 & 85 & 0.15 & 25 & 0.91 & 0.88 & 0.92 \\
\hline 14 & -20 & 85 & 0.15 & 25 & 0.5 & 0.48 & 0.47 \\
\hline 15 & -10 & 95 & 0.15 & 25 & 0.62 & 0.59 & 0.57 \\
\hline 16 & -20 & 95 & 0.15 & 25 & 0.38 & 0.31 & 0.37 \\
\hline
\end{tabular}

\begin{tabular}{|c|c|c|c|c|c|c|}
\hline \multicolumn{7}{|c|}{ Analysis of Variance for Res (coded units) } \\
\hline Source & $\mathrm{DF}$ & Seq SS & Adj SS & Adj MS & $\mathrm{F}$ & $\mathrm{P}$ \\
\hline Main Effects & 4 & 1.92929 & 1.92929 & 0.48232 & 516.77 & 0.000 \\
\hline Die & 1 & 1.41110 & 1.41110 & 1.41110 & 1511.90 & 0.000 \\
\hline Temp & 1 & 0.50225 & 0.50225 & 0.50225 & 538.13 & 0.000 \\
\hline Space & 1 & 0.01367 & 0.01367 & 0.01367 & 14.65 & 0.001 \\
\hline Time & 1 & 0.00227 & 0.00227 & 0.00227 & 2.43 & 0.129 \\
\hline 2-Way Interactions & 6 & 0.00993 & 0.00993 & 0.00165 & 1.77 & 0.136 \\
\hline DiexTemp & 1 & 0.00500 & 0.00500 & 0.00500 & 5.36 & 0.027 \\
\hline Die`Space & 1 & 0.00110 & 0.00110 & 0.00110 & 1.18 & 0.285 \\
\hline Die*Time & 1 & 0.00005 & 0.00005 & 0.00005 & 0.06 & 0.815 \\
\hline Temp^Space & 1 & 0.00130 & 0.00130 & 0.00130 & 1.40 & 0.246 \\
\hline Temp*Time & 1 & 0.00047 & 0.00047 & 0.00047 & 0.50 & 0.484 \\
\hline Space*Time & 1 & 0.00200 & 0.00200 & 0.00200 & 2.15 & 0.153 \\
\hline 3-Way Interactions & 4 & 0.05009 & 0.05009 & 0.01252 & 13.42 & 0.000 \\
\hline Die*Temp*Space & 1 & 0.05005 & 0.05005 & 0.05005 & 53.63 & 0.000 \\
\hline Die*Temp*Time & 1 & 0.00000 & 0.00000 & 0.00000 & 0.00 & 0.963 \\
\hline Die*Space*Time & 1 & 0.00002 & 0.00002 & 0.00002 & 0.02 & 0.888 \\
\hline Temp*Space*Time & 1 & 0.00002 & 0.00002 & 0.00002 & 0.02 & 0.888 \\
\hline 4-Way Interactions & 1 & 0.00025 & 0.00025 & 0.00025 & 0.27 & 0.607 \\
\hline Die*Temp*Space*Time & 1 & 0.00025 & 0.00025 & 0.00025 & 0.27 & 0.607 \\
\hline Residual Error & 32 & 0.02987 & 0.02987 & 0.00093 & & \\
\hline Pure Error & 32 & 0.02987 & 0.02987 & 0.00093 & & \\
\hline Total & 47 & 2.01943 & & & & \\
\hline
\end{tabular}

Fig 4 Shows Statistical Results of the Screening Phase at 99\% Confidence Limit.

In this experiment, the duck feed pellet production process were studied in batch of $30 \mathrm{~kg}$ each. The results of the analysis of variance (ANOVA) demonstrate that all three variables including "the thickness of die", "the distance between compression rollers and die, and "the temperature of mill machine needed during compressing the duck feed pellet production parameters" have a significantly influence on the product defects cause from dust problem (with p-value $<1 \%$ ) during 48 test runs. The statistical analysis was run using Minitab statistical software. The data also indicates that the retention time needed to mix ingredients is not an interaction effect on this problem. Figure 4 shows statistical results of the screening phase at $99 \%$ confidence limit.

\section{RESULT AND CONCLUSION}

The $3^{\mathrm{k}}$ factorial experimental design was used to help the factory determine the most appropriate level for each factor. Three levels of each factor were considered; low $(-1)$, moderate (0), and high (1). The nine treatment combinations for each test run are shown in table 5. The research uses a $3^{\mathrm{k}}$ factorial experimental design at a $99 \%$ confidence level with three replicates by using a 
total of $3 \times 3 \times 3 \times 3=81$ test runs. The three-way ANOVA found an interaction between the three factors (the thickness of the die $x$ the distance between the compression rollers and the die $\times$ the temperature needed to mix the ingredients $)(\mathrm{F}=53.63$ and $\mathrm{P}-$ Value $=$ $0.00<0.01)$.

Results from Table 6 and Figure 5 show three factors (the thickness of the die, the distance between compression rollers and the die, and the temperature it takes to mix the ingredients) are the main significant effects. In looking at the interactions, (thickness of die and distance between compression rollers and die) and (thickness of die and temperature of mill machine needed during compressing the duck feed pellet production) shows significant interactions.

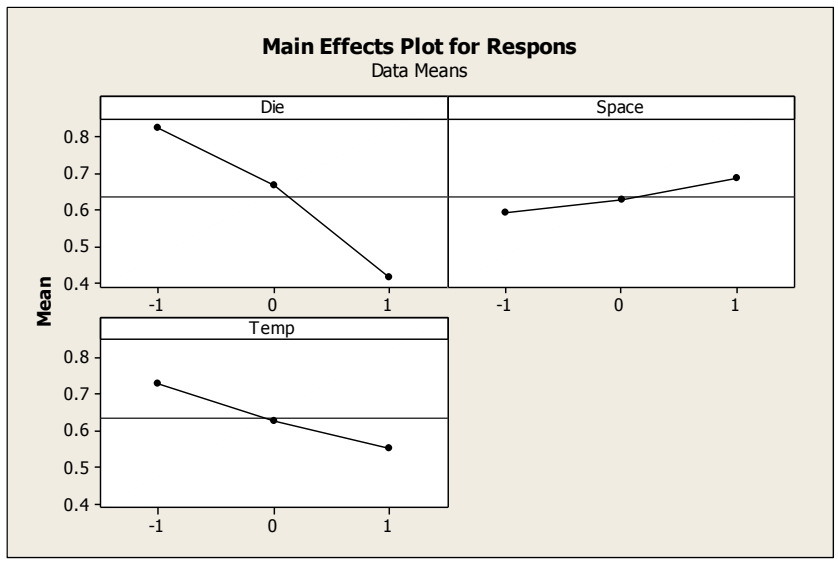

Fig 5 Main Effects for Response.

Table 5. Factors and Levels of the $3^{3}$ Factorial Design

\begin{tabular}{|l|c|c|c|c|}
\hline \multicolumn{2}{|c|}{ Factor } & \multicolumn{2}{c|}{ level } & unit \\
\cline { 2 - 5 } & Low level(-1) & Moderate level(0) & High level(1) & mm. \\
\hline (A) Distance between compression rollers and die & 0.05 & 0.1 & 95 & \multirow{2}{*}{ Celsius } \\
\hline $\begin{array}{l}\text { (B) Temperature of mill machine needed during } \\
\text { compressing the duck feed pellet production }\end{array}$ & 85 & 90 & -15 & mm. \\
\hline (D) Thickness of die & -10 & -15 & -20 & mm. \\
\hline
\end{tabular}

Table 6. Results of Experiments Factorial $3^{3}$ with Three Repeated Experiments.

\begin{tabular}{|c|c|c|c|c|c|c|}
\hline \multirow{3}{*}{ No. } & \multicolumn{3}{|c|}{ Factor } & \multicolumn{3}{|c|}{$\begin{array}{l}\text { Defects Proportion } \\
\text { (Replicate) }\end{array}$} \\
\hline & \multirow{2}{*}{$\begin{array}{l}\text { Thickness of die } \\
\text { (mm.) }\end{array}$} & \multirow{2}{*}{$\begin{array}{l}\text { Distance between compression } \\
\text { rollers and die } \\
\qquad(\mathrm{mm} .)\end{array}$} & \multirow{2}{*}{$\begin{array}{l}\text { Temperature of mill machine } \\
\text { needed during compressing the } \\
\text { duck feed pellet production } \\
\text { (Celsius) }\end{array}$} & $\begin{array}{c}1 \\
(\mathrm{Kg} .)\end{array}$ & $\begin{array}{c}2 \\
(\mathrm{Kg} .)\end{array}$ & $\begin{array}{c}3 \\
(\mathrm{Kg} .)\end{array}$ \\
\hline & & & & & & \\
\hline 1 & -10 & 0.05 & 85 & 0.85 & 0.87 & 0.83 \\
\hline 2 & -10 & 0.05 & 90 & 0.78 & 0.8 & 0.75 \\
\hline 3 & -10 & 0.05 & 95 & 0.69 & 0.73 & 0.7 \\
\hline 4 & -10 & 0.1 & 85 & 0.88 & 0.85 & 0.89 \\
\hline 5 & -10 & 0.1 & 90 & 0.83 & 0.79 & 0.8 \\
\hline 6 & -10 & 0.1 & 95 & 0.76 & 0.75 & 0.75 \\
\hline 7 & -10 & 0.15 & 85 & 0.95 & 0.89 & 0.96 \\
\hline 8 & -10 & 0.15 & 90 & 0.9 & 0.88 & 0.89 \\
\hline 9 & -10 & 0.15 & 95 & 0.83 & 0.8 & 0.84 \\
\hline 10 & -15 & 0.05 & 85 & 0.71 & 0.66 & 0.67 \\
\hline 11 & -15 & 0.05 & 90 & 0.6 & 0.62 & 0.61 \\
\hline 12 & -15 & 0.05 & 95 & 0.52 & 0.51 & 0.5 \\
\hline 13 & -15 & 0.1 & 85 & 0.74 & 0.73 & 0.74 \\
\hline
\end{tabular}


Juthamas Choomlucksana, / Journal of Engineering and Science Research, 2 (2), 2018, Pages: 26-33

\begin{tabular}{|c|c|c|c|c|c|c|}
\hline \multirow{3}{*}{ No. } & \multicolumn{3}{|c|}{ Factor } & \multicolumn{3}{|c|}{$\begin{array}{l}\text { Defects Proportion } \\
\text { (Replicate) }\end{array}$} \\
\hline & Thickness of die & $\begin{array}{l}\text { Distance between compression } \\
\text { rollers and die }\end{array}$ & Temperature of mill machine & $\begin{array}{c}1 \\
(\mathrm{Kg} .)\end{array}$ & $\begin{array}{c}2 \\
(\mathrm{Kg} .)\end{array}$ & $\begin{array}{c}3 \\
(\mathrm{Kg} .)\end{array}$ \\
\hline & & $(\mathrm{mm})$. & (Celsius) & & & \\
\hline 14 & -15 & 0.1 & 90 & 0.67 & 0.71 & 0.67 \\
\hline 15 & -15 & 0.1 & 95 & 0.56 & 0.55 & 0.58 \\
\hline 16 & -15 & 0.15 & 85 & 0.81 & 0.85 & 0.83 \\
\hline 17 & -15 & 0.15 & 90 & 0.72 & 0.74 & 0.75 \\
\hline 18 & -15 & 0.15 & 95 & 0.66 & 0.6 & 0.63 \\
\hline 19 & -20 & 0.05 & 85 & 0.53 & 0.51 & 0.56 \\
\hline 20 & -20 & 0.05 & 90 & 0.32 & 0.36 & 0.39 \\
\hline 21 & -20 & 0.05 & 95 & 0.29 & 0.3 & 0.26 \\
\hline 22 & -20 & 0.1 & 85 & 0.55 & 0.52 & 0.56 \\
\hline 23 & -20 & 0.1 & 90 & 0.38 & 0.35 & 0.39 \\
\hline 24 & -20 & 0.1 & 95 & 0.31 & 0.31 & 0.32 \\
\hline 25 & -20 & 0.15 & 85 & 0.56 & 0.55 & 0.58 \\
\hline 26 & -20 & 0.15 & 90 & 0.4 & 0.38 & 0.42 \\
\hline 27 & -20 & 0.15 & 95 & 0.37 & 0.39 & 0.35 \\
\hline
\end{tabular}

\begin{tabular}{|c|c|c|c|c|}
\hline \multicolumn{5}{|c|}{$\begin{array}{l}\text { Response Surface Regression: Respons versus Die, Space, Temp } \\
\text { The analysis was done using coded units. } \\
\text { Estimated Regression Coefficients for Respons }\end{array}$} \\
\hline Term & Coef & SE Coef & T & P \\
\hline Constant & 0.648889 & 0.008304 & 78.145 & 0.000 \\
\hline Die & -0.204259 & 0.003844 & -53.139 & 0.000 \\
\hline Space & 0.048333 & 0.003844 & 12.574 & 0.000 \\
\hline Temp & -0.088333 & 0.003844 & -22.980 & 0.000 \\
\hline Die*Die & -0.045000 & 0.006658 & -6.759 & 0.000 \\
\hline Space*Space & 0.010556 & 0.006658 & 1.585 & 0.117 \\
\hline Temp*Temp & 0.012778 & 0.006658 & 1.919 & 0.059 \\
\hline Die*Space & -0.012778 & 0.004708 & -2.714 & 0.008 \\
\hline Die`Temp & -0.025000 & 0.004708 & -5.310 & 0.000 \\
\hline Space *Temp & 0.005000 & 0.004708 & 1.062 & 0.292 \\
\hline $\begin{array}{l}\mathrm{S}=0.0282464 \\
\mathrm{R}-\mathrm{Sq}=98.07 \%\end{array}$ & $\begin{array}{ll}4 & \text { PRESS }= \\
\approx & \text { R-Sq (pred }\end{array}$ & $\begin{array}{l}0.0737861 \\
\text { d) }=97.488\end{array}$ & $\mathrm{R}-\mathrm{Sq}$ (a) & $d j)=97.82 \frac{8}{8}$ \\
\hline
\end{tabular}

Fig 6 Shows Statistical Results of the Screening Phase at 99\% Confidence Limit

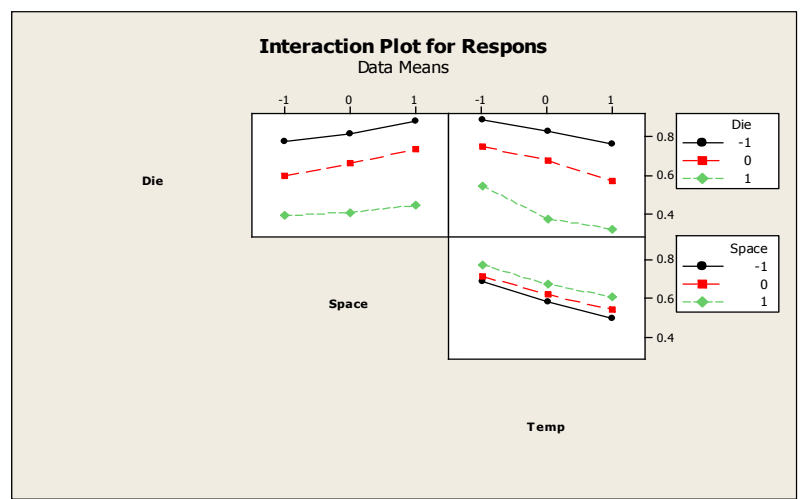

Fig 7 Interactions Plot for Three Factors

Equation 1 shows the generalized response research model.

$$
\begin{aligned}
y= & 0.6489-0.204259 x_{1}+0.0483 x_{2}-0.0883 x_{3}-0.045 x_{1}^{2}+0.01056 x_{2}^{2} \\
& +0.01278 x_{3}^{2}-0.01278 x_{1} x_{2}-0.025 x_{1} x_{3}+0.005 x_{2} x_{3}
\end{aligned}
$$


Juthamas Choomlucksana, / Journal of Engineering and Science Research, 2 (2), 2018, Pages: 26-33

where

$\mathrm{y}=$ proportion defects (Dust)

$\mathrm{x}_{1}=$ thickness of the die

$\mathrm{x}_{2}=$ distance between compression rollers and die

$\mathrm{x}_{3}=$ temperature of mill machine needed during compressing the duck feed pellet production

A response optimization was applied to find the appropriate level of each factors using Minitab software. The results are shown in figure 9 .

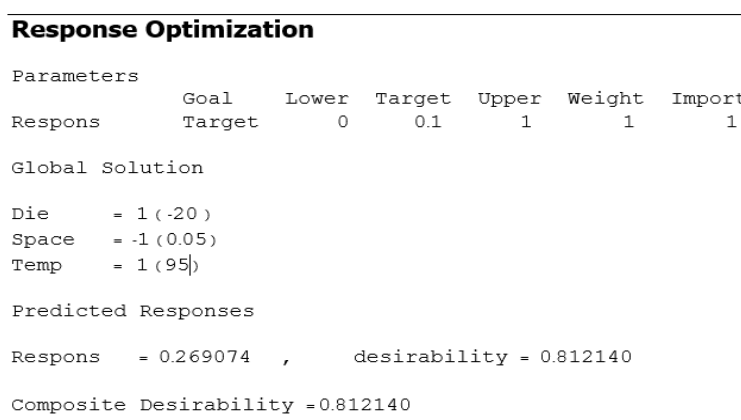

Fig 9 Response Optimization of Each Factor

\section{CONCLUSION}

The duck feed pellet product was the only product studied which requires more hardness than other feed. Several cause analysis techniques e.g. the Ishikawa diagram, Pareto chart, and FMEA (Failure Mode and Effects Analysis) were applied to find the main root cause and help the factory identify the potential and failure factors that influence on the duck feed pellet's quality. Problem from dust is the major problem according to customer complaint during January to July 2017. Three factors including the distance between compression rollers and die; the temperature of mill machine needed during compressing the duck feed pellet production, and retention time it takes to mix ingredients are the most important consideration factors that impact on the duck feed pellet quality problems. However, other factors such as the thickness of the die during pellet compression must be considered, as it may have an impact on the feed pellet quality by using $2^{\mathrm{k}}$ factorial design. In the experiment examining, "the distance between compression rollers and the die", "the temperature it takes to mix the ingredients", and "the thickness of the die during pellet compression" are identical for the main effect on product quality whereas, retention time it takes to mix ingredients is not an interaction effect of the defects problem.
The optimum values of these three factors were implemented in the duck feed pellet production process, which was tested for 3 months. The final outcome revealed a significant reduction of product defects that cause from dust problem from $2.51 \%$ to $1.09 \%$ $(\mathrm{P}<0.01)$. The response optimization was used to predict the exact optimum level of each variable. The findings indicate that an approximately of $-20 \mathrm{~mm}$. of thickness of die, $0.05 \mathrm{~mm}$ of distance between compression rollers and die, and 95 degree Celsius of temperature of mill machine needed during compressing the duck feed pellet production would be the most appropriate set of pelleting machine for the duck feed pellet production process. One limitation of the research study is that the number of trials has resulted in the factory production process .For this reason, the number of trials for this research study has been limited .

\section{ACKNOWLEDGMENTS}

This research was partially supported by the Graduate Thesis Research Grant (FTRG) from the Graduate College King Mongkut's University of Technology North Bangkok under award number 43/fiscal year 2561 (SUT), Thailand.

\section{REFERENCES}

[1] Panagiotis, H. T., and Dimitra, A. 2010. Application of failure modes and effects analysis (FMEA) of a ceramic titles manufacturing plant. Proceedings of the 1st Int. Conference on Supply Chains/Katerini. 1-17.

[2] Laura, A., Gerry, A., Maria, N., and Gillian, H. 2010. A practical guide to failure mode and effects analysis in health care: making the most of the team and its meetings. Joint Commission Journal on quality and Patient Safety 36(80), 351-358.

[3]Ioannis, S. A., and Theodoros, H.V. 2007. Application of failure mode and effect analysis (FMEA), cause and effect analysis and Pareto diagram in conjunction with HACCP to a potato chip manufacturing plant. International Journal of Food Science and Technology 42(12), 1424-1442.

[4]Siew-Hong, D., Nur, A,M., Noor, H.Z., and Amanina, N 2012. Application of integrated FMEA and fish bone analysis-a case study in semiconductor industry. In Proceeding of the 2012 International Conference on Industrial Engineering \& Operations Management, Istanbul, Turkey, July, 3-6 